Pesq. Vet. Bras. 29(9):725-730, setembro 2009

\title{
Níveis crescentes de parede de levedura sobre a resposta imune celular e perfil hematológico de frangos de corte ${ }^{1}$
}

\begin{abstract}
Suelen Regina Ferreira ${ }^{2}$, Alice E. Murakami $3^{*}$, Thais G.V. Siqueira ${ }^{3}$, José
Mauricio G. dos Santos ${ }^{4}$, Alexandra Potença ${ }^{3}$ e Tatiana Carlesso dos Santos ${ }^{3}$

ABSTRACT.- Ferreira S.R., Murakami A.E., Siqueira T.G.V., Santos J.M.G., Potença A. \& Santos T.C. 2009. [Cellular immune response and hematological parameters of broilers from different age broiler breeders, fed with a sorghum meal with different yeast wall levels.] Níveis crescentes de parede de levedura sobre a resposta imune celular e perfil hematológico de frangos de corte. Pesquisa Veterinária Brasileira 29(9):725-730, Universidade Estadual de Maringá, Av. Colombo 5790, Maringá, PR 87020-900, Brazil. E-mail: aemurakami@uem.br

An experiment was carried out to evaluate the effect increasing levels of yeast wall and broiler breeders' age levels on lymphoid organs weight, cellular immune response and hematological parameters in broilers. A total of 3,360 Cobb broilers were allotted, in a completely randomized design and a $2 \times 5$ factorial arrangement, and two controls, compound of two broiler breeders age ( 34 and 57 weeks of age) and five yeast wall levels (zero, one, two, three and four kg of yeast wall/ton of diet). Broiler breeders' age affected all studied variables. The inclusion of $3 \mathrm{~kg}$ of yeast wall/ton of meal increased, at 57 weeks age broiler breeders, more intense inflammatory reaction when compared to control diet; however the circulated heterophils and lymphocytes numbers were not increased. In conclusion, the use of yeast wall, associated or not to sorghum on broilers diet still needs complementary studies, for example, purified components of yeast wall (MOS and B-glucano).
\end{abstract}

INDEX TERMS: Hematology, immune response, sorghum, yeast wall.

RESUMO.- Um experimento foi conduzido para avaliar o efeito de níveis crescentes de parede de levedura e idade das matrizes reprodutoras sobre o peso dos órgãos linfóides, a resposta imune celular e o perfil hematológico de frangos de corte. Foram utilizados 3.360 pintos de corte da linhagem Cobb, distribuídos em delineamento inteiramente casualisado, em esquema fatorial $2 \times 5$, mais dois controles, sendo duas idades de matrizes (34 e 57 semanas de idade) e cinco níveis de suplementação de parede de levedura (zero, um, dois, três e quatro $\mathrm{kg}$ de parede de

${ }^{1}$ Recebido em 12 de janeiro de 2009.

Aceito para publicação em 5 de maio de 2009.

Parte da Tese de Doutorado do primeiro autor.

2 Empresa Abatedouro Coroaves, Rodovia BR 376 Km 427, Maringá, PR 87070-810, Brasil.

${ }^{3}$ Departamento de Zootecnia, Universidade Estadual de Maringá, Av. Colombo 5790, Maringá, Paraná 87020-900. *Autor para correspondência: aemurakami@uem.br

${ }^{4}$ Centro Universitário de Maringá, Av. Guedner 1610, Maringá, PR 87050-390. levedura/tonelada de ração). A idade das matrizes influenciou a resposta de todas as variáveis. A inclusão de $3 \mathrm{~kg}$ de parede de levedura/tonelada de ração promoveu, na progênie de reprodutoras de 57 semanas, reação inflamatória mais intensa quando comparada a dieta controle, no entanto não houve aumento significativo no número de heterófilos e linfócitos circulantes. Conclui-se que a utilização da parede de levedura associada ao sorgo ou não em rações de frangos de corte ainda necessita de estudos complementares, que incluam, por exemplo, os componentes purificados da parede de levedura (MOS e ß-glucano).

TERMOS DE INDEXAÇÃO: Hematologia, parede de levedura, resposta imune, sorgo.

\section{INTRODUÇÃO}

Os resultados da avicultura moderna são dependentes de fatores como genética, ambiente, nutrição e sanidade. Existe uma interdependência entre esses fatores e para atingir metas de produtividade, as pesquisas se concentram para melhor entender não só as necessidades fisiológicas das 
aves, mas também a fisiologia do sistema imune (Klasing 1998), permitindo assim que sob condições sanitárias adversas, as aves tenham menor perda de desempenho.

Entre os produtos estudados com objetivo de melhorar a resposta imune das aves contra agentes agressores encontram-se os mananoligossacarídeos (MOS) e os glucanos (Engstad \& Robertsen 1993). Estas substâncias têm sido aceitas como preventivo de quadros patológicos, especialmente os relacionados a bactérias entéricas como a Salmonella sp. (Spring et al. 2000), melhorando a microbiota intestinal e a eficiência dos processos digestivos. Esses compostos, derivados da parede celular de leveduras (Saccharomyces cerevisiae), foram utilizados inicialmente nas rações como prebiótico natural e hoje são estudados por sua ação sobre o sistema retículo endotelial, sendo considerados importantes no estímulo do sistema imune de aves e principalmente de seres humanos (Leblanc et al. 2006).

Os mananoligossacarídeos funcionam como sítios alternativos para a ligação de bactérias gram negativas (Ferket et al. 2002) e dessa forma evitam que o patógeno faça adesão nos enterócitos, dificultando a instalação de quadros infecciosos e, por conseqüência, melhorando a imunidade local do trato intestinal. Os mesmos autores relatam que uma das principais ações dos mananoligossacarídeos, quando comparados aos antibióticos, é a sua capacidade de prevenir a adesão e colonização de bactérias entéricas, apresentando ação específica sobre bactérias gram negativas com fímbrias F1 específicas para manose, colaborando assim para a integridade das células do intestino.

A produção de pintos de um dia é reflexo direto dos cuidados adotados no matrizeiro, especialmente biosseguridade e nutrição das reprodutoras. Um fator que deve ser considerado em especial é a idade das reprodutoras. Variáveis ligadas à idade da matriz podem influenciar diretamente sua progênie e, por conseqüência, o desempenho no campo e o resultado no abatedouro. A composição do ovo varia na quantidade de seus nutrientes como proteínas e lipídios com a idade das matrizes, e são maiores quando se tem reprodutoras mais velhas (Maiorka et al. 2003). Diferenças no teor de fósforo entre matrizes de 62 e 27 semanas foram relatadas por Vieira \& Moran (1998). Essa influência tem sido também estudada sob o aspecto imunitário, principalmente porque nos primeiros dias de vida, o pinto é dependente da imunidade materna transferida a ele via saco da gema (Kowalczyk et al. 1985).

O objetivo desse trabalho foi avaliar os efeitos da idade de matrizes e de diferentes níveis de suplementação de parede de levedura no peso dos órgãos linfóides, na resposta imune celular e no perfil hematológico de frangos de corte alimentados com dietas a base de sorgo substituindo o milho.

\section{MATERIAL E MÉTODOS}

O experimento foi realizado em aviário experimental, localizado em Maringá, PR. A estrutura do aviário atende os padrões técnicos, sendo construído em alvenaria, apresentando piso de concreto e mureta lateral de $40 \mathrm{~cm}$. O aviário é fechado com tela de arame até o telhado e apresenta sistema de cortinas móveis, sendo dotado de sistema de controle de temperatura, possuindo conjunto de ventiladores e nebulizadores, e sistema de aquecimento por forno a lenha. O galpão é dividido em 48 boxes, de $3,90 \times 1,50 \mathrm{~m}$, localizados na região central do aviário, com capacidade de 70 aves cada. Os comedouros são do tipo tubular e os bebedouros do tipo pendular. Para realização desse experimento foram utilizados 3360 pintos de corte machos da linhagem Cobb, sendo a metade proveniente de matrizes de 34 semanas e a outra metade de matrizes de 57 semanas de idade.

Foram fornecidas duas dietas basais, isoprotéicas, isoaminoacídicas e isocalóricas, com apresentação farelada, formuladas para atender as exigências mínimas conforme Rostagno et al. (2005). A primeira foi baseada em uma dieta tradicional à base de milho e soja e a segunda dieta formulada com $100 \%$ de sorgo. Ambas foram divididas em fase inicial (0-21 dias de idade) e fase de crescimento (22-42 dias de idade), atendendo as necessidades específicas de cada fase.

As rações experimentais foram produzidas pela unidade Rações do Abatedouro Coroaves Ltda e as matérias-primas utilizadas foram submetidas ao controle de qualidade adotado pela empresa. As análises envolveram a classificação de grãos, análises de proteína bruta, proteína solúvel, extrato etéreo, fibra bruta, cinzas (ANFAR 1998), análise de tanino (Nutron Alimentos LTDA) e dosagem de níveis de aflatoxina através de kit comercial (Ridasoft ${ }^{\circledR}$, Darmstadt, Germany) e leitura em leitor de densidade óptica (ELX-800) com filtro de 450nm.

A composição média da parede de levedura utilizada, segundo o fabricante, foi de no máximo $30 \%$ de proteína, máximo de $3,0 \%$ de fibra bruta, máximo de $6,9 \%$ de cinzas, ausência de aflatoxina e $25 \%$ de mananoligossacarídeos e $30 \%$ de B-glucanos.

As aves experimentais foram vacinadas com vacinas vivas e atenuadas. No $1^{\circ}$ dia no incubatório foram vacinadas contra a Doença de Marek e Doença de Gumboro (combinadas) e Bronquite Infecciosa das Galinhas em spray (MASS-I ${ }^{\circledR}$, Campinas, SP). № $7^{\circ}$ e $14^{\circ}$ dia foram vacinadas contra a Doença de Gumboro via água (Bursine Plus ${ }^{\circledR}$, Campinas, SP), e no 14을 dia foram vacinadas contra a Doença de NewCastle via água (Poulvac NDW enterotrópica ${ }^{\circledR}$, Campinas, SP).

$\mathrm{O}$ delineamento experimental utilizado foi inteiramente casualisado em esquema fatorial $2 \times 5$, sendo duas idades de matrizes (34 e 57 semanas) e cinco níveis de suplementação de parede de levedura $(0,1,2,3$ e $4 \mathrm{~kg} /$ tonelada), mais duas dietas (milho e farelo de soja) controle. Cada um dos 12 tratamentos foi composto de quatro repetições, com 70 aves cada, totalizando 3.360 aves.

Foram coletados o timo, a bolsa cloacal e o baço de duas aves por repetição, perfazendo um total de oito aves por tratamento, no $7^{\circ}$, $28^{\circ}$ e $42^{\circ}$ dia de idade. Para a realização dessa coleta, as aves foram submetidas ao sacrifício por deslocamento cervical, procedimento aprovado pelo Comitê de Conduta Ética no Uso de Animais em Experimentação da Universidade Estadual de Maringá (Parecer no 046/2006). Os órgãos coletados foram pesados em balança de precisão de um grama. Aferiu-se o peso vivo das aves, considerado como covariável durante o procedimento de análise. Utilizou-se também o peso relativo dos órgãos ((peso do órgão/peso vivo) * 100).

Aos 35 dias de idade, três aves por repetição, totalizando 12 aves por tratamento, foram marcadas com bastões marcadores, nas cores vermelho, azul e preto, foram utilizadas para avaliar a imunidade mediada por células in vivo (Corrier \& DeLoach 1990). Cada ave foi inoculada intradermicamente, no 
espaço interdigital entre o $3^{\circ}$ e $4^{\circ}$ dedo da pata direita com $0,1 \mathrm{~mL}$ de uma solução fitohemaglutinina $\mathrm{PHA}-\mathrm{M}^{\circledR}$ Campinas, SO, (1057601, Invitrogen). Como controle negativo, $0,1 \mathrm{~mL}$ de solução salina estéril foi inoculado entre o $3^{\circ}$ e $4^{\circ}$ dedo do pé esquerdo. O espessamento da pele de ambas as patas foi aferido em milímetros utilizando-se um paquímetro digital antes da inoculação e 3, 6, 12 e 24 horas após a inoculação. O cálculo (Corrier \& DeLoach 1990) apresentou-se da seguinte forma: Reação-resposta a fitohemaglutinina - resposta do controle, onde a resposta a fitohemaglutinina é medida pela espessura da pele após o tempo de inoculação menos a espessura no tempo zero (antes da inoculação). A resposta do controle é medida pela espessura da pele após o tempo de inoculação (PBS) menos a espessura no tempo zero (antes da inoculação).

Foram realizados hemogramas completos de três aves por repetição, totalizando 12 aves por tratamento, para avaliação do perfil hematológico eritrocitário (células vermelhas) e leucocitário (células brancas) das aves. As amostras de sangue com anticoagulante (EDTA) foram coletadas no $42^{\circ}$ dia de idade, por punção da veia jugular ou da veia braquial. As análises foram realizadas pelo método de Citometria Automatizada por Scatter Laser e Eletromagnética e a contagem diferencial leucocitária foi realizada por esfregaço sangüíneo (Laboratório São Camilo, Unidade de Análises Veterinárias, Maringá, PR).

Os dados foram submetidos à análise estatística utilizandose o programa Statistical Analysis System (SAS 2000). As variáveis peso dos órgãos linfóides, reação interdigital cutânea foram submetidas a análise de regressão polinomial admitindose distribuição normal e função de ligação identidade (Interactive Data Analysis). A variável hemograma foi submetida a análise de regressão admitindo-se distribuição gamma e função de ligação identidade (Interactive Data Analysis). O teste de Dunnett foi usado para comparação da dieta controle com as demais.

\section{RESULTADOS E DISCUSSÃO}

Os resultados do peso de órgãos linfóides (Quadros 1 e 2), reação interdigital cutânea (Quadro 3) e hemograma (Quadro 4), foram afetados pela idade das matrizes $(P \leq 0,05)$. Os órgãos linfóides têm seu desenvolvimento e posterior involução relacionados com o desenvolvimento corporal, que está relacionado com a idade das matrizes (Maiorka 2002, Maiorka et al. 2003). Entretanto, para as variáveis hematológicas da série vermelha, Luquetti et al. (2004) observaram que a idade das reprodutoras não refletiu diferenças na progênie.

O peso dos órgãos linfóides, considerando-se o peso das aves como covariável, não foi influenciado $(P>0,05)$ pelos níveis crescentes de parede de levedura na dieta. Dos órgãos avaliados, a bolsa cloacal e o timo são de fundamental importância para as aves, pois em seus compartimentos ocorre o processo de maturação dos linfócitos B e T, respectivamente (Glick 1986, Masteller \& Thompson 1994). As comparações entre os tratamentos mostraram que para aves descendentes de matrizes de 34 semanas aos 28 dias de idade, o tratamento que recebeu inclusão de $1 \mathrm{~kg}$ de parede de levedura/tonelada de ração, apresentou maior peso absoluto da bolsa cloacal $(\mathrm{P} \leq 0,05)$, quando comparado com o controle (milho), sugerindo um processo mais lento na involução do órgão ou então menor depleção linfocitária decorrente da vacinação. Os mesmos resultados foram encontrados para o peso relativo do órgão.

Na progênie de matrizes de 57 semanas, o efeito sobre o peso absoluto e relativo da bolsa cloacal também foi observado, sendo que nesse caso, a diferença ocorria

Quadro 1. Médias e erros padrão dos pesos absolutos $(\mathrm{g})$ e relativos (\%) dos órgãos linfóides para frangos de corte provenientes de matrizes com 34 semanas de idade, alimentados com uma dieta à base de sorgo e diferentes níveis de suplementação de parede de levedura (PL) comparados a uma dieta controle

\begin{tabular}{|c|c|c|c|c|c|c|}
\hline Dieta & $\begin{array}{l}07 \text { dias } \\
\text { Peso }(\mathrm{g})\end{array}$ & $\%$ & $\begin{array}{l}28 \text { dias } \\
\text { Peso }(\mathrm{g})\end{array}$ & $\%$ & $\begin{array}{c}42 \text { dias } \\
\text { Peso }(\mathrm{g})\end{array}$ & $\%$ \\
\hline & \multicolumn{6}{|c|}{ Timo } \\
\hline Milho (Controle) & $0,808 \pm 0,063$ & 0,49 & $7,667 \pm 0,767$ & 0,58 & $15,149 \pm 1,498$ & 0,54 \\
\hline Zero PL & $0,826 \pm 0,064$ & 0,47 & $7,282 \pm 0,688$ & 0,56 & $17,126 \pm 1,548$ & 0,62 \\
\hline $1 \mathrm{~kg} /$ tonelada $\mathrm{PL}$ & $=0,064$ & 0,48 & $7,602 \pm 0,682$ & 0,57 & $16,087 \pm$ & 0,58 \\
\hline $2 \mathrm{~kg} /$ tonelada $\mathrm{PL}$ & $0,747 \pm 0,064$ & 0,43 & $6,573 \pm 0,695$ & 0,49 & $17,566 \pm$ & 0,63 \\
\hline $3 \mathrm{~kg} /$ tonelada $\mathrm{PL}$ & $0,803 \pm 0,065$ & 0,47 & $8,096 \pm$ & 0,62 & $14,940=$ & 0,54 \\
\hline \multirow[t]{2}{*}{$4 \mathrm{~kg} /$ tonelada $\mathrm{PL}$} & $=0,064$ & 0,43 & $94 \pm 0,677$ & 0,48 & $15,623 \pm$ & 0,56 \\
\hline & \multicolumn{6}{|c|}{ Bolsa cloacal } \\
\hline Milho (Controle) & $0,332 \pm 0,029$ & 0,20 & $1,815 \pm 0,394^{b}$ & $0,14^{b}$ & $1,353 \pm 0,329$ & 0,05 \\
\hline Zero PL & $0,265 \pm 0,027$ & 0,15 & $3,115 \pm 0,410$ & 0,24 & $2,053 \pm$ & 0,07 \\
\hline $1 \mathrm{~kg} /$ tonelada $\mathrm{PL}$ & $0,348 \pm 0,027$ & 0,20 & $3,207 \pm 0,405^{a}$ & $0,24^{a}$ & $1,847 \pm 0,361$ & 0,07 \\
\hline $2 \mathrm{~kg} /$ tonelada $\mathrm{PL}$ & $0,309 \pm 0,027$ & 0,18 & $3,015 \pm 0,414$ & 0,23 & $2,220 \pm 0,359$ & 0,08 \\
\hline $3 \mathrm{~kg} /$ tonelada $\mathrm{PL}$ & $0,359 \pm 0,028$ & 0,21 & $2,941 \pm 0,412$ & 0,22 & 0,358 & 0,06 \\
\hline \multirow[t]{2}{*}{$4 \mathrm{~kg} /$ tonelada $\mathrm{PL}$} & $0,303 \pm 0,027$ & 0,17 & $2,460 \pm 0,403$ & 0,19 & $2,006 \pm 0,358$ & 0,07 \\
\hline & \multicolumn{6}{|c|}{ Baço } \\
\hline Milho (Controle) & $0,177 \pm 0,013$ & 0,11 & $1,530 \pm 0,184$ & 0,12 & & 0,12 \\
\hline Zero PL & $0,132 \pm 0,012$ & 0,08 & $1,391 \pm 0,179$ & & $3,198=$ & 0,12 \\
\hline $1 \mathrm{~kg} /$ tonelada $\mathrm{PL}$ & $0,127 \pm 0,012$ & 0,07 & $1,883 \pm 0,177$ & 0,1 & $3,987 \pm 0,266$ & 0,14 \\
\hline $2 \mathrm{~kg} /$ tonelada $\mathrm{PL}$ & $0,139 \pm 0,012$ & 0,08 & $1,809 \pm 0,181$ & 0,1 & $3,714 \pm 0,264$ & 0,14 \\
\hline $3 \mathrm{~kg} /$ tonelada $\mathrm{PL}$ & $0,153 \pm 0,012$ & 0,09 & $2,047 \pm 0,180$ & 0,16 & $3,638 \pm 0,263$ & 0,13 \\
\hline $4 \mathrm{~kg} /$ tonelada $\mathrm{PL}$ & $0,142 \pm 0,012$ & 0,08 & $1,816 \pm 0,176$ & 0,14 & $3,386 \pm 0,263$ & 0,12 \\
\hline
\end{tabular}

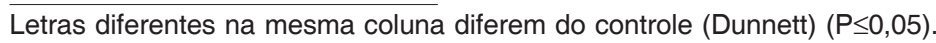


Quadro 2. Médias e erros padrão dos pesos absolutos (g) e relativos (\%) dos órgãos linfóides para frangos de corte provenientes de matrizes com 57 semanas de idade, alimentados com uma dieta à base de sorgo e diferentes níveis de suplementação de parede de levedura (PL) comparados a uma dieta controle

\begin{tabular}{|c|c|c|c|c|c|c|}
\hline Dieta & $\begin{array}{c}07 \text { dias } \\
\text { Peso }(\mathrm{g})\end{array}$ & $\%$ & $\begin{array}{l}28 \text { dias } \\
\text { Peso }(\mathrm{g})\end{array}$ & $\%$ & $\begin{array}{c}42 \text { dias } \\
\text { Peso }(\mathrm{g})\end{array}$ & $\%$ \\
\hline \multicolumn{7}{|c|}{ Timo } \\
\hline Milho (Controle) & $0,987 \pm 0,083$ & 0,52 & $6,445 \pm 3,187$ & 0,54 & $16,250 \pm 1,251$ & 0,55 \\
\hline Zero PL & $0,934 \pm 0,080$ & 0,49 & $6,413 \pm 3,422$ & 0,47 & $14,696 \pm 1,203$ & 0,50 \\
\hline $1 \mathrm{~kg} /$ tonelada $\mathrm{PL}$ & $0,942 \pm 0,080$ & 0,49 & $7,739 \pm 3,445$ & 0,46 & $14,983 \pm 1,206$ & 0,51 \\
\hline $2 \mathrm{~kg} /$ tonelada $\mathrm{PL}$ & $1,045 \pm 0,080$ & 0,54 & $8,936 \pm 3,453$ & 0,63 & $15,735 \pm 1,203$ & 0,54 \\
\hline $3 \mathrm{~kg} /$ tonelada $\mathrm{PL}$ & $0,920 \pm 0,080$ & 0,48 & $6,430 \pm 3,463$ & 0,55 & $15,802 \pm 1,247$ & 0,55 \\
\hline 4 kg/tonelada PL & $0,851 \pm 0,080$ & 0,45 & $7,098 \pm 3,443$ & 0,49 & $18,059 \pm 1,272$ & 0,61 \\
\hline \multicolumn{7}{|c|}{ Bolsa cloacal } \\
\hline Zero PL & $0,381 \pm 0,022$ & 0,20 & $2,804 \pm 0,450$ & 0,21 & $2,346 \pm 0,199$ & 0,08 \\
\hline $1 \mathrm{~kg} /$ tonelada PL & $0,383 \pm 0,022$ & 0,20 & $4,394 \pm 0,452$ & 0,33 & $2,018 \pm 0,199$ & 0,07 \\
\hline $2 \mathrm{~kg} /$ tonelada $\mathrm{PL}$ & $0,386 \pm 0,022$ & 0,20 & $3,495 \pm 0,453$ & 0,27 & $1,703 \pm 0,199$ & 0,06 \\
\hline $3 \mathrm{~kg} /$ tonelada $\mathrm{PL}$ & $0,333 \pm 0,022^{b}$ & $0,17^{\mathrm{b}}$ & $3,502 \pm 0,454$ & 0,26 & $1,782 \pm 0,206$ & 0,06 \\
\hline $4 \mathrm{~kg} /$ tonelada $\mathrm{PL}$ & $0,393 \pm 0,022$ & 0,21 & $2,922 \pm 0,452$ & 0,22 & $2,052 \pm 0,210$ & 0,07 \\
\hline \multicolumn{7}{|c|}{ Baço } \\
\hline Milho (Controle) & $0,137 \pm 0,012$ & 0,07 & $1,786 \pm 0,159$ & 0,13 & $4,606 \pm 0,450$ & 0,15 \\
\hline Zero PL & $0,136 \pm 0,012$ & 0,07 & $1,583 \pm 0,160$ & 0,12 & $3,786 \pm 0,361$ & 0,13 \\
\hline $1 \mathrm{~kg} /$ tonelada $\mathrm{PL}$ & $0,138 \pm 0,012$ & 0,07 & $1,640 \pm 0,160$ & 0,12 & $3,751 \pm 0,362$ & 0,13 \\
\hline $2 \mathrm{~kg} /$ tonelada $\mathrm{PL}$ & $0,174 \pm 0,012$ & 0,09 & $1,798 \pm 0,161$ & 0,14 & $3,471 \pm 0,361$ & 0,12 \\
\hline $3 \mathrm{~kg} /$ tonelada $\mathrm{PL}$ & $0,165 \pm 0,012$ & 0,09 & $1,761 \pm 0,161$ & 0,13 & $3,920 \pm 0,374$ & 0,14 \\
\hline $4 \mathrm{~kg} /$ tonelada $\mathrm{PL}$ & $0,133 \pm 0,012$ & 0,07 & $1,687 \pm 0,160$ & 0,13 & $3,805 \pm 0,382$ & 0,13 \\
\hline
\end{tabular}

Letras diferentes na mesma coluna diferem do controle (Dunnett) $(P \leq 0,05)$.

entre a dieta com milho e a dieta com inclusão de $3 \mathrm{~kg}$ de parede de levedura/tonelada de ração $(P \leq 0,05)$ em aves com sete dias de idade, com peso do órgão superior na dieta contendo milho. Para essa situação considerou-se que, o processo inicial de desenvolvimento na bolsa cloacal foi mais lento nesse nível de inclusão, visto que nas demais idades essa diferença não foi identificada. Nas demais situações e demais órgãos a adição ou não da parede de levedura não resultou em maior peso $(P>0,05)$.

Os níveis utilizados nos tratamentos não afetaram $(P>0,05)$ o peso do timo e do baço em nenhuma das ida- des consideradas. No caso do timo, órgão fundamental para a maturação dos linfócitos T (Abbas et al. 2007), pode-se considerar que a parede de levedura não auxiliaria na imunidade celular, responsável pelo ataque direto a microrganismos, entretanto é fundamental considerar que maior peso dos órgãos não reflete necessariamente maior número de células linfóides.

O tratamento a base de sorgo, sem suplementação de parede de levedura, que seria equivalente ao tratamento contendo milho, não diferenciou do milho $(P>0,05)$, indicando que em caso de substituição, o sorgo não

Quadro 3. Média e erros padrão da reação interdigital a fitohemaglutinina $(\mathrm{mm})$ em frangos de corte provenientes de matrizes com 34 e 57 semanas de idade alimentados com dietas à base de sorgo com diferentes níveis de suplementação de parede de levedura (PL) comparados a uma dieta controle

\begin{tabular}{ccccc}
\hline Dieta & $03 \mathrm{~h}$ & $06 \mathrm{~h}$ & $12 \mathrm{~h}$ & $24 \mathrm{~h}$ \\
& \multicolumn{4}{c}{34 semanas } \\
\hline Milho (Controle) & $1,170 \pm 0,141$ & $0,510 \pm 0,081$ & $0,469 \pm 0,097$ & $0,493 \pm 0,097$ \\
Zero PL & $1,342 \pm 0,141$ & $0,445 \pm 0,081$ & $0,654 \pm 0,097$ & $0,639 \pm 0,097$ \\
$1 \mathrm{~kg} /$ tonelada PL & $1,060 \pm 0,141$ & $0,539 \pm 0,081$ & $0,552 \pm 0,097$ & $0,639 \pm 0,097$ \\
$2 \mathrm{~kg} /$ tonelada PL & $0,896 \pm 0,141$ & $0,399 \pm 0,081$ & $0,395 \pm 0,097$ & $0,405 \pm 0,097$ \\
$3 \mathrm{~kg} /$ tonelada PL & $1,137 \pm 0,141$ & $0,532 \pm 0,081$ & $0,573 \pm 0,097$ & $0,488 \pm 0,097$ \\
$4 \mathrm{~kg} /$ tonelada PL & $1,249 \pm 0,141$ & $0,553 \pm 0,081$ & $0,572 \pm 0,097$ & $0,437 \pm 0,097$ \\
& \multicolumn{4}{c}{57 semanas } \\
Milho (Controle) & $1,100 \pm 0,186$ & $0,541 \pm 0,099$ & $0,473 \pm 0,103$ & $0,418 \pm 0,096^{\mathrm{b}}$ \\
Zero PL & $1,052 \pm 0,186$ & $0,498 \pm 0,099$ & $0,565 \pm 0,103$ & $0,526 \pm 0,096$ \\
$1 \mathrm{~kg} /$ tonelada PL & $1,347 \pm 0,186$ & $0,637 \pm 0,099$ & $0,619 \pm 0,103$ & $0,476 \pm 0,096$ \\
$2 \mathrm{~kg} /$ tonelada PL & $1,162 \pm 0,186$ & $0,545 \pm 0,099$ & $0,430 \pm 0,103$ & $0,474 \pm 0,096$ \\
$3 \mathrm{~kg} /$ tonelada PL & $1,436 \pm 0,186$ & $0,875 \pm 0,099$ & $0,757 \pm 0,103$ & $0,814 \pm 0,096^{\mathrm{a}}$ \\
$4 \mathrm{~kg} /$ tonelada PL & $1,496 \pm 0,186$ & $0,670 \pm 0,099$ & $0,548 \pm 0,103$ & $0,707 \pm 0,096$
\end{tabular}

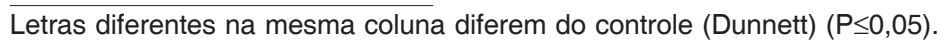




\begin{tabular}{|c|c|c|c|c|c|c|}
\hline $\begin{array}{l}\text { Dieta } \\
\text { Idade }\end{array}$ & $\begin{array}{c}\text { Eritrócito } \\
\left(10^{3} \mathrm{cls} / \mathrm{mm}^{3}\right)\end{array}$ & $\begin{array}{l}\text { Hemoglobina } \\
(\mathrm{g} / \mathrm{dl})\end{array}$ & $\begin{array}{c}\text { Hematócrito } \\
(\%)\end{array}$ & $\begin{array}{l}\text { Leucócito } \\
\left(\mathrm{mm}^{3}\right)\end{array}$ & $\begin{array}{l}\text { Heterófilos } \\
\left(\mathrm{mm}^{3}\right)\end{array}$ & $\begin{array}{l}\text { Linfócitos } \\
\left(\mathrm{mm}^{3}\right)\end{array}$ \\
\hline & \multicolumn{6}{|c|}{ Matriz 34 semanas } \\
\hline Milho (Controle) & $2.586 \pm 55.100^{\mathrm{a}}$ & $12,57 \pm 0,245^{a}$ & $34,10 \pm 0,619^{a}$ & $17.375 \pm 1.222$ & $4.131 \pm 618$ & $12.969 \pm 1.248$ \\
\hline Zero PL & $2.513 \pm 50.500$ & $12,33 \pm 0,227$ & $33,52 \pm 0,573$ & $16.278 \pm 1.0$ & & $11.915 \pm 1.081$ \\
\hline $1 \mathrm{~kg} /$ tonelada PL & $2.455 \pm 44.600$ & $11,93 \pm 0,198^{b}$ & $32,04 \pm 0,496^{b}$ & $14.954 \pm 897$ & $4.089 \pm$ & $10.496 \pm 862$ \\
\hline $2 \mathrm{~kg} /$ tonelada $\mathrm{PL}$ & $2.464 \pm 44.800$ & $12,18 \pm 0,203$ & $32,72 \pm 0,506$ & & 556 & $75 \pm 893$ \\
\hline $3 \mathrm{~kg} /$ tonelada $\mathrm{PL}$ & $2.407 \pm 45.900^{b}$ & $11,90 \pm 0,208^{b}$ & $32,44 \pm 0,526^{b}$ & 922 & $22 \pm 538$ & $1 \pm 958$ \\
\hline $4 \mathrm{~kg} /$ tonelada $\mathrm{PL}$ & $2.637 \pm 53.000$ & $12,87 \pm 0,237$ & $34,82 \pm 0,596$ & $13.367 \pm 886$ & $4.008 \pm 565$ & $8.991 \pm 816$ \\
\hline Idade & \multicolumn{6}{|c|}{ Matriz 57 semanas } \\
\hline Milho (Controle) & $2.613 \pm 50.500$ & $12,81 \pm 0,230$ & $34,68 \pm 0,625$ & $15.422 \pm 1.528$ & $4.464 \pm 886$ & $10.272 \pm 1.081^{\mathrm{a}}$ \\
\hline Zero PL & $2.619 \pm 48.000$ & $12,76 \pm 0,217$ & $34,21 \pm 0,585$ & $12.780 \pm 1.201$ & $4.756 \pm 895$ & $7.589 \pm 758^{b}$ \\
\hline $1 \mathrm{~kg} /$ tonelada $\mathrm{PL}$ & $2.617 \pm 48.000$ & $12,78 \pm 0,218$ & $34,83 \pm 0,596$ & $16.000 \pm 1.504$ & $3.889 \pm 732$ & $11.587 \pm 1.157$ \\
\hline $2 \mathrm{~kg} /$ tonelada $\mathrm{PL}$ & $2.620 \pm 62.000$ & $12,85 \pm 0,282$ & $34,48 \pm 0,761$ & $16.117 \pm 1.955$ & $2.929 \pm 712$ & $12.865 \pm 1.658$ \\
\hline $3 \mathrm{~kg} /$ tonelada $\mathrm{PL}$ & $2.681 \pm 58.800$ & $13,07 \pm 0,266$ & $35,53 \pm 0,726$ & $14.143 \pm 1.589$ & $4.213 \pm 948$ & $9.613 \pm 1.147$ \\
\hline $4 \mathrm{~kg} /$ tonelada $\mathrm{PL}$ & $2.590 \pm 75.000$ & $12,70 \pm 0,342$ & $34,72 \pm 0,939$ & $14.750 \pm 2.192$ & $4.067 \pm 1.211$ & $10.235 \pm 1.616$ \\
\hline
\end{tabular}

Letras diferentes na mesma coluna diferem do controle (Dunnett) $(P \leq 0,05)$.

traria prejuízo ao desenvolvimento dos órgãos linfóides.

A resposta celular interdigital cutânea após injeção de fitohemaglutinina (PHA) não foi influenciada pelos níveis de parede de levedura adicionados à dieta ou pelo tipo de dieta, sorgo ou milho $(P>0,05)$. Dessa forma, conclui-se que dietas exclusivamente à base de sorgo não trariam influência direta nas reações de hipersensibilidade cutânea ou ao processo inflamatório geral $(P>0,05)$. No presente experimento, diferenciando-se de observações anteriores (Lessard et al. 1997), a reação inflamatória inicial foi detectada mais precocemente, com três horas, caracterizando uma reação de hipersensibilidade.

Quando comparado ao milho, o tratamento a base de sorgo mostrou valores superiores $(P \leq 0,05)$ para inclusão de $3 \mathrm{~kg}$ de parede de levedura/tonelada de ração após 24 horas de observação na progênie de reprodutoras de 57 semanas, demonstrando haver reação de hipersensibilidade mais intensa e possivelmente um processo inflamatório de resolução mais lenta. Os componentes da parede de levedura, os mananoligossacarídeos e os Bglucanos têm sido considerados como importantes agentes na modulação da resposta imune em perus (Cetin et al. 2005) e em frangos (Shashidhara \& Devegowda 2003, Lowry et al. 2005). Sob o aspecto reação inflamatória e inativação de bactérias, Lowry et al. (2005) observaram uma melhor atividade fagocítica e de destruição bacteriana, por heterófilos isolados de aves que receberam uma dieta contendo ß-glucanos purificados. Entretanto, destaca-se que, nos casos de hipersensibilidade, as células comumente envolvidas são os basófilos (Abbas et al. 2007). Os resultados podem ser decorrentes da condição sanitária das aves, provenientes de reprodutoras saudáveis, alojados em condições ideais de temperatura e densidade, e dentro de um quadro de biosseguridade considerado estável que, mesmo sob situação de indução de resposta inflamatória, promovida por agente estimulador externo (PHA), não respondeu aos níveis crescentes de parede de levedura, entretanto, apresentaram reação ao estímulo provocado.

Quando um agente patógeno inicia seu ataque a qualquer organismo, várias reações fisiológicas acontecem, provocando quadros febris, reação inflamatória e por conseqüência a ativação da resposta específica esperada, nesse caso, entretanto, não foram evidenciados efeitos positivos dos níveis do produto testado sobre a resposta imune mediada por células.

Considerando-se os resultados do perfil hematológico, apenas a progênie descendente de matrizes de 34 semanas foi influenciada pelos níveis de parede de levedura da dieta. Os parâmetros afetados $(P \leq 0,05)$ foram os números de eritrócitos $\left(\mathrm{Y}=2,5232-0,1022 \mathrm{PL}+0,0289 \mathrm{PL}^{2}\right)$, a hemoglobina $\left(Y=12,3170-0,4209 \mathrm{PL}+0,1254 \mathrm{PL}^{2}\right)$ e o hematócrito $\left(\mathrm{Y}=33,3989-1,4249 \mathrm{PL}+0,4225 \mathrm{PL}^{2}\right)$, com pontos de mínimo com suplementação de 1,77kg, 1,68kg e 1,69kg de parede de levedura/tonelada respectivamente. Os resultados encontrados divergem dos observados por Cetin et al. (2005) que verificaram que aves que receberam suplementação de $1 \mathrm{~g}$ de $\mathrm{MOS} / \mathrm{kg}$ de ração não apresentaram alterações no perfil eritrocitário.

No leucograma, o resultado obtido encontra-se em acordo com Cetin et al. (2005), em que a contagem de leucócitos totais e a contagem diferencial não foram afetadas $(P>0,05)$ pela suplementação proposta, nem em níveis superiores, ou seja, os mananoligossacarídeos e/ ou os ß-glucanos, não melhoraram, em números absolutos, e sem ocorrência de quadro clínico, uma das primeiras linhas de defesa das aves, os heterófilos. A mesma consideração pode ser feita para os linfócitos circulantes.

A comparação com a dieta controle, na progênie de matrizes de 34 semanas, na contagem de eritrócito foi superior à dieta com sorgo com inclusão de $3 \mathrm{~kg}$ de parede de levedura/tonelada de ração $(P \leq 0,05)$. Considerando-se a hemoglobina e o hematócrito, o milho foi superior à inclusão de 1 e $3 \mathrm{~kg}$ de parede de levedura/tonelada de ração em dietas à base de sorgo. A dieta à base de sorgo, 
isenta de suplementação com parede de levedura, não se diferenciou da dieta contendo milho $(P>0,05)$, considerando-se as variáveis eritrocíticas. Na progênie de matrizes de 57 semanas observou-se superioridade do milho apenas na contagem de linfócitos em relação à dieta sem suplementação de parede de levedura.

Apesar da ação da parede de levedura sobre o sistema imune, citados pela literatura, os resultados observados nesse trabalho não demonstraram efeito sobre a maioria dos parâmetros analisados. Sendo assim, conclui-se que a utilização da parede de levedura associada ao sorgo ou não em rações de frangos de corte ainda necessita de estudos complementares, que incluam, por exemplo, a purificação da parede de levedura nos seus principais componentes (MOS e ß-glucano).

\section{REFERÊNCIAS}

Abbas A.K., Lichtman A.H. \& Pillai S. 2007. Cellular and Molecular Immunology. 6th ed. Saunders Elsevier, Philadelphia. 566p.

ANFAR 1998. Compêndio Brasileiro de Alimentação Animal. Sindirações/ ANFAR/CBNA/SDRMA, São Paulo. 197p.

Cetin N., Guclu B.K. \& Cetin E. 2005. The effects of probiotic and mannanoligosaccharide on some hematological and immunological parameters in turkeys. J. Vet. Med. 52(6):263-267.

Corrier D.E. \& DeLoach J.R. 1990. Evaluation of cell-mediated, cutaneous basophil hypersensitivity in young chickens by an interdigital skin test. Poult. Sci. 69(3):403-408.

Engstad R.E. \& Robertsen B. 1993. Recognition of yeast cell wall glucan by Atlantic salmon (Salmo salar L.) macrophages. Dev. Comp. Immunol. 17:319-330.

Ferket P.R., Parks C.W. \& Grimes J.L. 2002. Benefits of dietary antibiotic and mannanoligosaccharide supplementation for poultry. Proc. Multi-State Poultry Meeting, Indianapolis. University of Illinois, Indianopolis, p.22.

Glick B. 1986. Immunophysiology, p.87-101. In: Sturkie P.D. (Ed.), Avian Physiology. 4th ed. Kingsport Press, Tennessee. 685p.

Klasing K.C. 1998. Nutritional modulation of resistance to infectious diseases. Poult. Sci. 77(8):1119-1125.
Kowalczyk K., Daiss J., Halpern J. \& Roth T.F. 1985. Quantitation of maternal-fetal IgG transport in the chicken. Immunology 54:755-762.

Lessard M., Huthings D. \& Cave N.A. 1997. Cell-mediated and humoral immune responses in broiler chickens maintained on diets containing different levels of vitamin A. Poult. Sci. 76(10):1368-1378.

Leblanc B.W., Albina J.E. \& Reichner J.S. 2006. The effect of PGG- $\beta$ glucan on neutrophil chemotaxis in vitro. J. Leucoc. Biol. 79:667-675.

Lowry V.K., Farnell M.B., Ferro P.J., Swaggerty C.L., Bahl A. \& Kogut M.H. 2005. Purified beta-glucan as an abiotic feed additive up-regulates the innate immune response in immature chickens against Salmonella enterica serovar Enteritidis. Poult. Sci. 98(3):309-318.

Luquetti B.C., Gonzales E., Bruno L.D.G., Furlan R.L \& Macari M. 2004. Egg traits and physiological neonatal chick parameters from broiler breeder at different ages. Braz. J. Poult. Sci. 6(1):13-17.

Maiorka A. 2002. Efeitos da idade da matriz, do jejum, da energia da ração e da glutamina sobre o desenvolvimento da mucosa intestinal e atividade enzimática do pâncreas de pintos de corte. Tese de Doutorado em Zootecnia, Faculdade de Ciências Agrárias e Veterinárias, Universidade Estadual Paulista, Jaboticabal. 103p.

Maiorka A., Luquetti B.C., Almeida J.G. \& Macari M. 2003. Idade da matriz e qualidade do pintinho, p.361-377. In: Macari M. \& Gonzáles E. (Eds), Manejo da Incubação. Facta, Campinas. 526p.

Masteller E.L. \& Thompson C.B. 1994. B cell development in the chicken. Poult. Sci. 73(7):998-1011.

Rostagno H.S., Albino L.F.T., Donzele J.L., Gomes P.C., Oliveira R.F., Lopes D.C., Ferreira A.S. \& Barreto S.L.T. 2005. Tabelas Brasileiras para Aves e Suínos: composição de alimentos e exigências nutricionais. Departamento de Zootecnia, UFV, Viçosa. 186p.

SAS Institute Inc. 2000. Statistical Analysis System, Versão 8.0. Cary, NC. (Manual Online)

Shashidhara R.G. \& Devegowda G. 2003. Effect of dietary mannan oligosaccharide on broiler breeder production traits and immunity. Poult. Sci. 82(8):1319-1325.

Spring P., Wenk C., Dawson K.A. \& Newman K.E. 2000. The effects of dietary mannanoligosaccharide on cecal parameters and the concentrations of enteric bacteria in the ceca samonella-challenged broiler chicks. Poult. Sci. 79(2):205-211.

Vieira S.L. \& Moran E.T. 1998. Eggs and chicks from broiler breeders of extremely different age. J. Appl. Poultry Res. 7(4):372-376. 